University of Wollongong

Research Online

Vice-Chancellor's Unit

1997

\title{
Why pragmatic impairment? A case study in the comprehension of inferential meaning
}

Eeva K. Leinonen

University of Wollongong, leinonen@uow.edu.au

Carolyn Letts

Follow this and additional works at: https://ro.uow.edu.au/vc

\section{Recommended Citation}

Leinonen, Eeva K. and Letts, Carolyn, "Why pragmatic impairment? A case study in the comprehension of inferential meaning" (1997). Vice-Chancellor's Unit. 55.

https://ro.uow.edu.au/vc/55

Research Online is the open access institutional repository for the University of Wollongong. For further information contact the UOW Library: research-pubs@uow.edu.au 


\title{
Why pragmatic impairment? A case study in the comprehension of inferential meaning
}

\begin{abstract}
This paper discusses a case study of Sarah (aged 9;8-10;3) who is reported to have pragmatic difficulties. The focus is on her comprehension of questions, which are asked on the basis of pictures and heard stories. Particular focus is on the pragmatic (or inferential) demands of the input questions and their relationship to the (in)appropriacy of the answer. Data from 16 normally functioning 6- and 8-year-old children are also presented for comparative purposes. The study shows that Sarah has difficulty with questions which require her to go beyond visually presented or verbally stated information. On one set of tasks she was to answer questions on the basis of composite pictures: for some of the questions, the answer was obvious from the picture (descriptive questions) and for others information needed to be inferred beyond the picture (for example, by imagining what had happened before and what is likely to happen next). Sarah's performance was poorer on the inferential questions than the descriptive questions and poorer than the performance of 6- and 8-year-old normally functioning control children. Although the control children also found the inferential questions more difficult than the descriptive questions, this difficulty was not as pronounced as Sarah's. This trend was also apparent in a set of tasks which required the children to answer questions on the basis of verbally told stories. This study suggests that pragmatically impaired children may have difficulty going beyond explicitly presented information and this would manifest as pragmatic production and comprehension problems. In cognitive terms, this may indicate difficulty with the process of inferencing.
\end{abstract}

\section{Keywords}

inferential, comprehension, study, case, meaning, impairment, why, pragmatic

\section{Publication Details}

Leinonen, E. K. \& Letts, C. (1997). Why pragmatic impairment? A case study in the comprehension of inferential meaning. European Journal of Disorders of Communication, 32 (2s), 35-51. 


\title{
Why pragmatic impairment? A case study in the comprehension of inferential meaning
}

\author{
EEVA LEINONEN \\ University of Hertfordshire, $U K$ \\ CAROLYN LETTS \\ University of Reading, $U K$
}

\begin{abstract}
This paper discusses a case study of Sarah (aged 9;8-10;3) who is reported to have pragmatic difficulties. The focus is on her comprehension of questions, which are asked on the basis of pictures and heard stories. Particular focus is on the pragmatic (or inferential) demands of the input questions and their relationship to the (in)appropriacy of the answer. Data from 16 normally functioning 6-and 8-year-old children are also presented for comparative purposes. The study shows that Sarah has difficulty with questions which require her to go beyond visually presented or verbally stated information. On one set of tasks she was to answer questions on the basis of composite pictures: for some of the questions, the answer was obvious from the picture (descriptive questions) and for others information needed to be inferred beyond the picture (for example, by imagining what had happened before and what is likely to happen next). Sarah's performance was poorer on the inferential questions than the descriptive questions and poorer than the performance of 6- and 8year-old normally functioning control children. Although the control children also found the inferential questions more difficult than the descriptive questions, this difficulty was not as pronounced as Sarah's. This trend was also apparent in a set of tasks which required the children to answer questions on the basis of verbally told stories. This study suggests that pragmatically impaired children may have difficulty going beyond explicitly presented information and this would manifest as pragmatic production and comprehension problems. In cognitive terms, this may indicate difficulty with the process of inferencing.
\end{abstract}

Key words: inferencing, pragmatic comprehension, pragmatic impairment.

\section{INTRODUCTION}

The question why a child may be said to have pragmatic difficulties or pragmatic impairment is one which is currently being asked by researchers and other speech and language professionals in the UK. There is some feeling that a bandwagon may have been created somewhat too hastily and that people may have been too eager to jump on to this relatively unknown vehicle. There are numerous issues to address before we can, with any confidence, say that a child has a pragmatic impairment. Indeed, we need to ask first whether such impairments exist at all, and in what form.

It has been acknowledged for some time now that children may have pragmatic and communication difficulties in addition to linguistic dysfunctioning (Fey \& Leonard, 1983; Baltaxe \& D'Angiola, 1992; Craig \& Evans, 1993). The 
question of whether pragmatic difficulties can exist separately from linguistic problems has also been subject to both theoretical and empirical debate (Bishop \& Adams, 1989; McTear \& Conti-Ramsden, 1992; Smith \& Leinonen, 1992; Bishop, Hartley \& Weir, 1994). Such studies have highlighted that pragmatically impaired children tend to exhibit inappropriate conversational behaviours (such as giving too much or too little information; excessive use of initiations; expression superior to comprehension; problems with topic maintenance). Studies have also drawn attention to the fact that these surface behaviours may have very different underlying causes, thus rendering the subject population heterogeneous and the existence of different subtypes highly probable.

Language disordered children typically have widely varying profiles of impairment, and this variable pattern is also apparent with any group that might be labelled pragmatically impaired. For some individuals, it may be possible to see how pragmatic behaviour is secondary to other linguistic problems, for example, limited vocabulary or syntactic comprehension, or expressive limitations, leading to output that is misunderstood, or to patterns of avoidance that are perceived as pragmatically bizarre. For others, a linguistic explanation for the pragmatic problems may not seem likely, and cognitive deficits may be the cause (McTear \& Conti-Ramsden, 1992). Further possibilities include lack of social skill, inhibiting communicative environment or simply lack of confidence. The identification of a 'pure' pragmatic disorder, independent of linguistic and cognitive deficits is problematical, and indeed it is possible that such disorders cannot exist. The issue is further complicated by the fact that pragmatic impairment is usually diagnosed rather impressionistically (given the lack of rigorous diagnostic tools), often on the basis of some kind of checklist of behaviours. Children with different subsets of behaviours and different underlying causes may all be diagnosed as pragmatically impaired.

Almost every study of children's pragmatic difficulties refers to potential or actual comprehension problems that such children experience. Both in clinical reports and research (Prutting \& Kirchner, 1983; Rapin \& Allen, 1983, 1987; McTear, 1985; Conti-Ramsden \& Gunn, 1986; Jones, Smedley \& Jennings, 1986; Culloden, Hyde-Wright \& Shipman, 1986; Bishop \& Rosenbloom, 1987; Adams \& Bishop, 1989; Bishop \& Adams, 1989; Hyde-Wright \& Cray, 1991) frequent reference is found to difficulties which (can) reflect poor pragmatic comprehension. These include:

- Expression superior to comprehension.

- Problems in 'using context in comprehension'.

- Difficulties with non-literal messages.

- Difficulties with answering questions.

- Problems with conversational topics which are divorced from the here and now.

- Poor topic maintenance.

- Poor understanding of cause-effect and temporal-causal relationships.

- Problems with verbal reasoning.

- Difficulty of making inferences about actions.

- Inflexible style of making inferences.

- Difficulty in processing whole utterances or selecting relevant parts.

- Tendency to give too much or too little information. 
The potential role of comprehension in pragmatic impairment has been further acknowledged in clinical pragmatic profiles, which include categories for focusing on comprehension deficits.

\section{Language Comprehension}

What is it to comprehend a language expression? It is perhaps needless to say that there is no clear answer to this question. It is, however, common to differentiate between linguistic (syntactic and semantic) comprehension and comprehension in pragmatic terms. The former involves understanding of the meanings of individual words in sentences and how the sentence structure plays a role in assigning meaning to the expression. In linguistic comprehension no reference needs to be made to contexts in which the sentence may occur, but the comprehender simply makes reference to his linguistic knowledge. Therefore, in order to comprehend the sentence 'Mary lives just around the corner' linguistically, we need not worry who Mary is and whether she lives around the corner or who the speaker of the sentence is. Theories of comprehension (Johnson-Laird, 1983; Sperber \& Wilson, 1986) believe that linguistic comprehension plays a role in the comprehension of language expressions, but is only the beginning of the comprehension process.

The above example about Mary shows that we cannot comprehend on the basis of grammar and words alone, since the expression is intrinsically tied to the context in which it is uttered. We need to know who Mary is and who the speaker is (reference assignment) in order to work out what is meant beyond the linguistic meaning. Most communicative expressions have meaning beyond the linguistically stated. The above expression, could mean, for instance, 'I am pleased/not pleased about Mary living just around the corner' or 'I don't have far to take my children to play'. Meaning that is found in (worked out on the basis of) context is called pragmatic meaning and hence comprehension of such meaning can be called pragmatic comprehension. The context may involve, for instance, the physical context ('he is married to her not her'; speaker is nodding in the appropriate directions), the speaker intention ('That is very hot'; description or warning) or previous verbal context ('I met Mary in town today. She was alone'). Bringing the context to bear in comprehension is said to involve the cognitive process of inferencing (see Stevenson, 1993). Inferencing refers to 'making connections' between sets of knowledge with the view to coming up with an outcome. In pragmatic comprehension, we need to bring together information from the linguistic expression, the context and our internal world knowledge to work out the possible intended meaning. We say 'possible intended meaning' since communication is essentially an uncertain process, given that we are only making guesses as to the intended meaning on the basis of the linguistic expression and any available evidence.

\section{Children's Comprehension of Questions}

When children become competent comprehenders of language this process can be said to involve, in the terms of Milosky (1992):

increasingly sophisticated uses of context. Development will be characterized in terms of increasing fluidity or lack of rigidity in using context and by changes in the amount and type of knowledge children acquire and use for dealing with the basic indeterminacy in language. (p. 21) 
From a very early age children are able to combine information to work out meanings (to infer), but this becomes more sophisticated with their developing ability to make connections on the basis of more subtle clues and beyond the immediate context. The ability of children to answer questions is also connected with their increasing competence in understanding pragmatic meanings. The grammatical form of the question can have an effect on the ease or difficulty for the child to answer the question (for example, labelling questions or yes/no questions are easier to answer than open-ended questions), yet it is ultimately the pragmatic or functional requirements of questions which have a strong bearing on the appropriacy of answers. The presence or absence of objects that are talked about are part of the pragmatic environment that affects the ability of a child to provide adequate answers (Parnell \& Amerman, 1983). A further effect of the role of the pragmatic demands of questions on children's answers is seen when a child can answer a question of a particular grammatical form in one context but not in another. In these instances, it cannot be the linguistic form that causes the problem, but the situational demands are likely to play a role. Parnell and Amerman (1983) maintain that when considering children's mastery of question understanding, it is important not only to consider the structural nature of questions but also the child's:

- Understanding of the purpose of the question.

- Understanding of the semantics of the proposition.

- Understanding of his/her own role as the recipient of the question.

- Willingness to fulfill the respondent role.

- World knowledge to draw upon.

Pragmatically informed research needs to address the kinds of variables which bear on children's understanding of questions, with gathering more information about the extent and type of questioning present in different communicative context (for example, school).

\section{Poor Comprehenders}

Children's comprehension skills can vary considerably. Work, particularly in psychology, has looked into the development of inferential skills in comprehension of language and discourse. Studies by Oakhill and colleagues (Oakhill, 1984; Oakhill \& Yuill, 1986; Oakhill, Yuill \& Parkin, 1986) have suggested that 7-8-year-old less-skilled comprehenders may find it difficult to keep track of pronoun (or anaphoric) links in discourse. They may also have difficulty with accessing pragmatic or inferential meanings in input texts, thus suggesting that their poor comprehension abilities reflected difficulty with the process of inferencing. Poor working memory and lack of world knowledge were ruled out as contributing to the children's poor comprehension skills. Oakhill (1984) suggest that remedial procedures could usefully focus on the construction of meaning from text and on bringing knowledge from outside the text into this process. It may also be useful to teach strategies for organising and retrieving information.

It is now well-attested that language disordered children may have cognitively based difficulties (Bishop, 1991; Johnston, 1992). Work by Shields, Var- 
ley, Broks and Simpson (1996) further show that pragmatically impaired children have similar difficulties in social cognition (for example, theory of mind) as highly functioning autistic children, thus suggesting a cognitively rather than linguistically based explanation for their pragmatic difficulties. Other language disordered children (syntactic-phonologic) did not perform poorly on social cognition tasks in the study. Cognitive deficits are likely to affect pragmatic comprehension ability, given that the cognitive process of inferencing is central to pragmatic comprehension. Weismer's (1985) study of a group of language disordered children (aged 7;10-8;11) points to a cognitively based deficit which hinders the children's ability to piece together information and 'read between the lines' in order to arrive at a full understanding of a message. Crais and Chapman (1987) arrived at a similar conclusion in their study of story recall and inferencing skills of older (9-10-year-old) language disordered children. Their study pointed to further difficulties with 'on-the-spot' inferencing in story recall which, in turn, may be tied to difficulties of general 'on-line' processing. The work of Kelly, Borrill and Maddell (1996) further suggests that careful thought could be given to assessment of executive or frontal lobe functioning in the autistic spectrum children, given that such function is related to goaldirected and purposeful activity, including the ability to integrate information into a coherent whole. The link to pragmatic comprehension difficulties is apparent, given that integration (or inferencing) is central to the process.

Craig and Evans (1993) make the point that the pragmatic and discourse skills of speech and language impaired (SLI) children may vary relative to their language comprehension abilities. They found that SLI children with expressive and receptive deficits performed significantly worse on certain measures of turntaking and cohesion than children with primarily expressive deficits. These differences could not be explained by a reduced linguistic repertoire, but rather the answer seemed to lie more solidly in the children's comprehension difficulties. There is a need to consider further the comprehension abilities of SLI (and pragmatically impaired) children in studies which focus on pragmatic meaning.

There are two published studies to date that focus specifically on pragmatic comprehension abilities of pragmatically impaired children (Bishop \& Adams, 1992; Vance \& Wells 1994). In the 1992 study of Bishop and Adams, SLI, semantic-pragmatic disordered (SPD) and normal control children were asked descriptive and inferential questions on the basis of verbally and/or pictorially presented stories. A descriptive question was one where the answer was mentioned in the story or explicitly shown in the pictures. Inferential questions, on the other hand, required the children to go beyond the explicitly mentioned or explicitly presented. Overall, both the SLI and SPD children performed significantly worse than the control group, yet the question type (descriptive versus inferential) or mode of presentation (verbal or pictorial) did not differentiate between the groups. There was, however, a non-significant trend for the SPD group to perform more poorly than the other SLI children on the inferential questions.

The Vance and Wells (1994) study found no significant differences of SLI, SPD and control children's comprehension of idioms and metaphors in a set of tasks. This finding did not, however, accord with clinical observations which would describe the SPD children as having 'a poor ability to use context to 
deduce meaning' (p. 38). These authors suggest that one possible explanation for this discrepancy may be that in open-ended communicative situations the SPD children do not realise that a non-literal interpretation is required while this realisation is more easy to come by in a well-defined experimental context (see Bishop \& Adams, 1991). There are several other possible explanations for the findings, one resting on the nature of idioms and metaphors themselves. There is a possibility that at least some of the input expressions (for example, 'raining cats and dogs'; 'be in the dog house'; 'bull in a china shop') could have been learned as whole lexical items, thus calling primarily for linguistic rather than pragmatic comprehension.

This paper reports on a case study of a child (aged 9;8-10;3) who is considered to have pragmatic difficulties. The focus will be on the child's pragmatic comprehension. The child attends a language unit in a mainstream school in the UK. A number of language (including narrative) and non-verbal tasks have been carried out over an eight-month period. This paper explores data from two types of task. The focus will be on the child's comprehension of questions which, in turn, will shed some light on the reported poor performance of the child as a conversational partner. A cognitive explanation is a possibility for the observed comprehension difficulties. This, in turn, can be related to pragmatic comprehension difficulties. Control data from 6- and 8-year-old normally functioning children for the four tasks will also be discussed.

\section{CASE STUDY: SARAH}

\section{Conversational Performance}

Sarah was studied for an eight-month period, starting when she was aged 9;8. By talking to Sarah's speech and language therapist and her class teacher, the following types of surface behaviours can be seen as leading to the label 'pragmatically impaired' being applied to Sarah:

- Relatively good expressive language skills.

- Irrelevant contributions in conversation.

- Comprehension problems in conversation.

- Problems with time and space concepts.

- Problems with extended discourse, including narrative construction.

Despite these kinds of difficulties, the first impression of Sarah was that she was very eager to communicate, and very skilled at the mechanics of communication. This initial impression was supported by two pragmatic profiles (McTear, 1985; Prutting \& Kirchner, 1983) which were initially used to gain an informal view of her as a communicator. These profiles showed that Sarah was able to engage in conversation by responding minimally and in extended turns, by initiating (primarily by the use of statements), by using cohesive devices such as conjunctions, pronouns and ellipsis, by responding to requests for confirmation and specification and by, even, requesting clarification herself. The profiles did show some difficulties too and these fell into inappropriate response categories.

It became clear early on that Sarah's conversational difficulties were not always evident, that they probably occurred under fairly specific conditions. 
This intermittency provided a starting point for trying to identify some of the conditions under which the difficulties surfaced which, it was hypothesised, would enable the exploration of whether the pinpointed problems could be described as being pragmatic in nature. It is within this background that this paper explores the nature of adult questions which were followed by Sarah's inappropriate responses. Before looking at this, however, Sarah's linguistic functioning is described briefly.

\section{Linguistic Profile}

Sarah's reading was reported to be good and this was partly confirmed by several tasks which required her to read aloud. Initial exploration of the data indicates that she tends not to read for meaning but rather seems to concentrate on the mechanics of reading.

Sarah's expressive syntax was also reported to be good. LARSP (Crystal, Fletcher \& Garman, 1976) analysis indicated that she is able to use a wide variety of structures, including a range of complex sentence types. Although most of these structures are in place by about age 4;6 in children with normal language development some are notoriously difficult for language impaired children to acquire. Hence a LARSP analysis completed on the language of an impaired child over the age of 4-5 years can be revealing. In Sarah's case, no syntactic difficulties were apparent. The data did, however, reveal some formulation difficulties as evidenced by hesitation phenomena, such as pauses (filled or otherwise) and repetitions, and false starts followed by re-formulation of structures. Such difficulties tended to occur in predictable places in the data (for example, when Sarah was beginning an unfamiliar task; when she was introducing a new topic; when she was confabulating). Formulation difficulties did not interfere with decisions as to the appropriacy of a response. They were not in themselves considered inappropriate, since they occur normally in speech and are considered to be a reflection of increased processing load.

Sarah's syntactic comprehension, however, appears poor, as assessed by the Test for Reception of Grammar (TROG) (Bishop 1982). At the age of 8;10 Sarah achieved a score which was equivalent of age 5;3. At age 10;2 her TROG (Bishop, 1982) score was the same.

Problems with narrative construction were also evident at age 8;10 when Sarah obtained a score which was age equivalent of 4;0 on Renfrew's (1969) 'Bus Story'. This score was only marginally better at age 10;1.

Problems with vocabulary comprehension at age 10;2 are shown in the British Picture Vocabulary Scale (BPVS) (Dunn, Dunn, Whetton \& Pintilie, 1982) score which was age equivalent of 6;11.

Sarah's non-verbal intelligence has been tested and she was considered normally functioning (no access to the scores).

With this information in mind it would seem that Sarah's communication difficulties could be at least partly attributed to her linguistic difficulties, primarily to syntactic comprehension and vocabulary comprehension. But, a wholesale adoption of this explanation does not address the intermittency of her communication problems. It does not explain why the same syntactic structures can be comprehended in some contexts but not in others. Sarah, for instance, failed the TROG (Bishop, 1982) block containing the expressions 'the cup is in the 
box', 'the pencil is on the box', 'the circle is in the star' and 'the knife is on the shoe' but was capable of appropriately producing, comprehending and acting upon instructions such as the following on a referential communication task: 'Put a yellow pencil and a spoon in the cup', 'Put a large red brick on the plate' or 'Put two blue pencils in the box'. It would seem that a linguistic explanation alone would not address such variable performance, but some other view of the difficulties would need to be evoked. It is frequently mentioned that children with language and communication difficulties may perform differently in different contexts or at different times. This has been attributed to the nature of the task, the effect of interactive partners or other contextual effects. Cognitive and, perhaps, pragmatic explanations can also be offered and we will return to this after the data.

\section{CONTROL SUBJECTS}

Rather than follow a single-case study design, it was decided to include control data from 6- and 8-year-old normally functioning children in the study. Not only did we wish to make some comparisons (admittedly inconclusive given the size of the data) between Sarah's performance and that of others, we also wanted to gauge the suitability of the material for children close to Sarah's level of linguistic functioning. It was felt that the use of control children of the same age as Sarah would not be particularly revealing, as they would be considerably more sophisticated linguistically. The 6-year-old group was to some extent matched to Sarah's comprehension age, although her syntactic comprehension was below the 6-year-old level. At the same time, having a group of 8year-olds permitted any possible developmental patterns to be seen.

Data was obtained from 16 linguistically normally functioning children, eight 6-year-olds and eight 8-year-olds, (four boys and four girls in each group).

\section{METHOD}

Data was obtained on the basis of four tasks. Tasks 1 and 2 consist of two composite pictures: 'The Park' and 'The Flood'. The tasks were performed at different times with Sarah, but at one sitting with the control group. The children were asked to look at the pictures for a while and then they were asked questions about them. Some of the questions were descriptive (i.e. the answer was visually evident in the picture) and others required varying levels of inferencing beyond the picture itself. The children were also asked to justify their answers to the inferential questions ('Why is that?' 'How can you tell that?'), which involve inferencing beyond the visually presented information in the pictures.

In Task 3 the children were read a short story, Ice Skating (as in Bishop \& Adams, 1992) which went with a sequence of four pictures. They were then asked questions about it, some of which were descriptive, some of which were inferential (and some questions which required the children to justify their answers). The answer was either evident in the story and/or pictures or had to be inferred beyond the story and the pictures. Task 4 is a variant of Task 3 . The children were read a story, Piggy Bank (as in Bishop \& Adams, 1992) without pictures, and again were asked the two types of question. 
The following examples illustrate how a question was deemed to be a descriptive or an inferential one:

- Descriptive questions:

Is there a man in the hut?

How many trees are there?

(There is a man in a hut in the picture.)

How many garden tools are there?

(There are six trees in the picture.)

(There are four tools in the picture.)

- Inferential questions:

Are the men going to do any more work?

Context: There are two men sitting on a bench in the park in work overalls. One is reading a newspaper and the other is eating sandwiches. In front of them are garden tools (e.g. a fork and a spade) which are next to a hole dug in the ground. Next to the hole lies a tree to be planted and to the right of the hole are two newly planted trees. Given all this information in the picture it would be highly likely that the two men had been planting trees in the park and are now having a break and will continue to plant the last tree in the hole which they dug prior to their break. To arrive at this context, which will then enable one to answer the above question in the most appropriate way (i.e. to arrive at the most likely answer as supported by the visually available evidence), one needs to put together information from the picture and one's world knowledge (i.e. one needs to infer beyond the picture). The question itself also gives a clue as to the most probable context which is needed for answering the question (i.e. '...any more work' implies that the men did some work previously).

What is the hole for?

Context: As above. Most likely answer: To plant the tree in the hole to which it is lying next to.

Did the flood happen quickly or slowly?

Context: There is a flooded river in the picture with the current carrying household items, a cow, trees and people clinging to bits of wood down the river. It looks like the flood had caught people unawares. People in the town next to the river have also been caught out, since they are standing on the roofs of their cars. Given this pictorial evidence together with one's world knowledge, that if people had time to prepare for a slowly raising river, they would have not been caught unawares as in the picture. Hence, it is likely that the flood happened quickly rather than slowly. Again, to arrive at this likely conclusion one needs to make inference on the basis of the picture and one's world knowledge.

It is worth noting that an inferential question needs to be followed by a question asking for the reason for the given answer (for example, 'Why do you say that?' 'How can you tell that?'). This enables the context to be explored on the basis of which the answer was arrived at and hence explore the reasoning (inferencing) underlying the answer. This helps to determine the appropriacy of the answer in relation to the question and the visually available evidence. It is also worth considering that questions may require different degrees of inferencing (perhaps related to complexity), reflecting factors such as the number of inferences to be drawn, the familiarity and obviousness of given information, the nature and availability of world knowledge and the effectiveness of processing capacity. Given the complexity of these kinds of factors, it has not been possible to take them into account in this study, but the authors are aware that the inferential questions are likely to vary in the demands that they place on the children.

\section{DATA ANALYSIS}

The purpose of this study is to examine whether any pattern can be found with regard to the nature of adult questions which led to Sarah's inappropriate responses. Two researchers worked independently on parts of Sarah's data for 
which inter-rater reliability scores were calculated. For the four tasks, identifying (in)appropriate responses was relatively straightforward and a high level of agreement was obtained by the two researchers $(>90 \%)$.

It is notoriously difficult to identify inappropriacy in discourse (Leinonen \& Smith, 1994). This difficulty largely reflects the differing abilities of people in placing an interpretation on the utterances of others, as well as their different levels of tolerance towards the somewhat unusual. Lack of developmental norms of pragmatic behaviour also renders inappropriacy judgements problematic. This study aimed to minimise the difficulty of making (in)appropriacy judgements, by choosing relatively well-defined tasks which delimit the range of possible appropriate answers. In the picture tasks, the visual input defines to a large extent how the questions can be answered. There may be some variability, but within the confines of the pictures. Similarly, the verbal input of the stories place boundaries for possible interpretations. Hence, the appropriacy of answers was interpreted strictly within the confines of the given interpretative contexts, and hence unavoidably, some interesting and creative answers which did not match the contexts were deemed inappropriate. For instance, Sarah's answer to the question 'What is the hole for?' was 'I think it's for to put a treasure in it'. This was deemed inappropriate given that it did not match the context of the picture at all. Sarah was not able to say how she arrived at this interpretation either.

For the descriptive questions, identifying the appropriacy of the answer simply involves checking whether the given answer matches the picture or the verbal story. Where the question involved the counting of instances (for example, a number of trees), any number was accepted as an appropriate answer. In other words, the child was not being tested on her ability to count, but rather on her realisation that the question required her to count.

For the inferential questions, identifying (in)appropriacy of answers involves the follow-up question which focuses on the reason for the answer (see above). This enables a judgement to be made as to whether the reasoning matches the available evidence (in other words, could the available evidence lead to the given reasoning). If not, then the answer was deemed inappropriate. If the child was not able to give a coherent or any reason, this was also categorised as an inappropriate answer. Given the small number of children involved in this study, it was decided not to have any fine-grained categories for inappropriacy, but it could be interesting in a larger study to consider types of inappropriate answers (for example, 'don't know').

The study also looks briefly at the linguistic form of the adult question and its relationship to the (in)appropriacy of Sarah's answers.

\section{RESULTS}

The results are interpreted with the design of the study in mind. This is a case study which includes a small amount of data from control children primarily with the view to validating the tasks. Hence, the results are inconclusive with regard to the general population.

Table 1 summarises the overall results for the four tasks in terms of the percentage of appropriate or inappropriate answers given by Sarah to the adult questions. Although Sarah's performance lacks any strong trends here, we can make some interesting observations. 
Table 1: Percentage of appropriate/inappropriate answers to adult questions (Sarah)

\begin{tabular}{lccc}
\hline & Appropriate & Inappropriate & $\boldsymbol{N}$ \\
\hline Task 1 & 62 & 39 & 13 \\
Task 2 & 32 & 68 & 37 \\
Task 3 & 86 & 14 & 14 \\
Task 4 & 50 & 50 & 10 \\
\hline
\end{tabular}

Firstly, we can note that the percentages are more or less opposite for tasks 1 and 2. These tasks were identical in format, but they consisted of different numbers of descriptive and inferential questions. Table 2 summarises the number of inferential and descriptive questions which led to appropriate or inappropriate answers in the four tasks. Table 2 also shows that Task 2 had inferential questions only and that most of them were answered inappropriately. This difference may explain, in part, why Sarah had more difficulty answering the questions in Task 2 than in Task 1, thus suggesting potential problems with answering inferential questions.

Table 2: Number of descriptive and inferential questions, as a function of the appropriacy of the answer

\begin{tabular}{lcccc}
\hline & \multicolumn{2}{c}{ Descriptive } & \multicolumn{2}{c}{ Inferential } \\
& Appropriate & Inappropriate & Appropriate & Inappropriate \\
\hline Task 1 & 5 & 1 & 2 & 5 \\
Task 2 & 0 & 0 & 6 & 31 \\
Task 3 & 7 & 0 & 5 & 2 \\
Task 4 & 3 & 3 & 2 & 2 \\
\hline
\end{tabular}

The one descriptive question in the picture tasks that Sarah answered inappropriately was the first question asked ('Is there a man in the hut?'). Although she did not appear distracted at the time, it may well have been that Sarah was not yet paying attention adequately. Examples of appropriately answered inferential questions in tasks 1 and 2 included 'What season of the year is it?' in Task 1, to which Sarah answered 'I think it's spring' and when asked to justify this she said 'It's a sunny day' and in Task 2 the question 'Are the rescue services in action yet?' was answered 'No, there isn't any rescuers'. The latter answer gives a descriptive account of the picture, which does not have any rescue services in it. Examples of inappropriate answers in the two tasks include the following:

Task 1: (see the Method section above for the context for interpreting the examples)

Q: Are the men going to do any more work?

A: No.

Q: Why is that?

A: Because they (mumbled syllables) have the rest.

$\mathrm{Q}$ : What is the hole for?

A: I think it is to put a treasure in it.

Q: Why do you say that?

A: 0 
Task 2:
Q: Did the flood happen during the night?
A: No.
Q: Why is that?
A: Because its I can see a sunny day.

(Context: It looks like the flood had happened in the morning/day since people have been caught unawares going about their everyday lives, standing on top of cars, etc.)
Q: Is the telephone system working?
A: Umm No.
Q: Why is that?
A: Because I can see one there. I think it's a basket actually. That's a basket.

(Context: There are telephone lines fallen down in the picture.)

Looking at these few examples of inappropriate answers to inferential questions, it is clear that the answers can be inappropriate in different ways and we have not attempted in this study to disentangle these differences, primarily because of the size of the sample. What the opposite pattern of answers in tasks 1 and 2 simply alerts us to is that for some reason the questions which involve going beyond the picture itself are more problematical for Sarah that the descriptive questions.

Table 1 above also shows that the percentage of appropriate answers on Task $3(86 \%)$ was higher than on Task $4(50 \%)$. Task 3 involved both a heard story and pictures on the basis of which the questions were answered. Visual clues were missing from Task 4, which can therefore be assumed to put more reliance on memory and inferencing from memory. It is of course a possibility that the two stories had differing conceptual structures, thus rendering one more difficulty than the other and thus drawing upon different kinds of world knowledge.

The data on the four tasks indicates that Sarah had difficulty answering questions which involved manipulation of inferential meaning. These results do not enable us to say why these difficulties may surface. It may be that Sarah:

- Has problems with the cognitive process of inferencing per se.

- Does not have problems with inferencing, but has problems with inferencing from memory, especially when minimal immediate or obvious (e.g. visual) clues are available.

- Does not have problems with inferencing, but does not have the required world knowledge to understand what is going on in the picture/stories.

Sarah's difficulty with Task 2 may also reflect greater conceptual complexity of the Flood picture as compared with the Park picture. The inferential complexity (see Method section above) of the Flood questions may also have a role to play.

We also considered the possibility that the grammatical form of the question may correlate with the appropriacy/inappropriacy of Sarah's answers, thus potentially suggesting a more linguistically motivated comprehension problem. Table 3 shows an analysis of question form and Sarah's appropriate/inappropriate answers. 
Table 3: Percentage of appropriate/inappropriate answers as a function of the question form

\begin{tabular}{lcccc}
\hline & \multicolumn{2}{c}{ Task 1 + Task 2 } & \multicolumn{2}{c}{ Task 3 + Task 4 } \\
& Appropriate & Inappropriate & Appropriate & Inappropriate \\
\hline Y/N & 45 & 44 & 0 & 14 \\
What - nominal & 20 & 0 & 24 & 43 \\
What - verb & 10 & 4 & 12 & 0 \\
WH - adjective & 10 & 4 & 0 & 0 \\
WH - time & 0 & 4 & 0 & 0 \\
WH - loc & 5 & 0 & 12 & 0 \\
Why & 5 & 38 & 29 & 29 \\
Who & 0 & 0 & 12 & 0 \\
How & 1 & 0 & 6 & 0 \\
Choice & 1 & 0 & 6 & 0 \\
Other & 5 & 4 & 0 & 0 \\
$N$ & 20 & 30 & 17 & 7 \\
\hline
\end{tabular}

In broad terms what this analysis indicates is that there is no definite relationship between the form of the question and the nature of the answer or the type of data, except for one tendency: why questions tend to lead to inappropriate answers across the board, except for the story condition based on pictures. (These figures are very small, however.)

We have also explored the possibility that linguistically normally functioning children might show difficulty with the processing of inferential meaning, as presented in these tasks. The control data from 16 linguistically normally functioning children, eight 6 -year-olds and eight 8 -year-olds, ( 4 boys and 4 girls in each age group) is summarised in Table 4.

Table 4: Percentage of appropriate/inappropriate answers to adult questions control data $(N=16)$

\begin{tabular}{|c|c|c|c|c|c|}
\hline & \multicolumn{2}{|c|}{ 6-year-olds $(N=8)$} & \multicolumn{2}{|c|}{ 8-year-olds $(N=8)$} & \multirow[t]{2}{*}{$\boldsymbol{N}$} \\
\hline & Appropriate & Inappropriate & Appropriate & Inappropriate & \\
\hline Task 1 & 84 & 16 & 89 & 11 & 80 \\
\hline Task 2 & 74 & 26 & 77 & 23 & 144 \\
\hline Task 3 & 90 & 10 & 96 & 4 & 112 \\
\hline Task 4 & 77 & 23 & 84 & 13 & 80 \\
\hline
\end{tabular}

Looking at tasks 1 and 2 first, this table indicates that both 6- and 8-year-olds had more appropriate answers than inappropriate answers on both tasks, even though the percentage of appropriate answers was slightly lower in Task 2 than in Task 1. This data indicates that the children were able to take part in this task, they understood the situations presented to them and the questions asked. Table 4 above also shows that on the verbal story tasks (tasks 3 and 4) children in the control group in both age groups had more appropriate answers than inappropriate answers. The percentage of appropriate answers for the story plus pictures (Task 3 ) was higher for both groups than for the story only condition (Task 4). This may indicate some difficulty answering questions from memory alone. The performance of the two age groups across all the tasks was 
very similar, indicating that at age 6 children were already able to answer the types of questions presented in these tasks.

It is not appropriate to make direct comparisons of a single-case and a group of children. We can, however, observe that Sarah did not produce such high numbers of appropriate answers to the inferential questions as the children in the control groups. She had a similar pattern of answers (i.e. more appropriate than inappropriate) as the control children, except for Task 2, which she found particularly difficult. Similarly, the questions on Task 4 were difficult for Sarah in a more pronounced way than for the children in the control groups. Difficulty with remembering was offered by several of the children in the control groups as a reason for struggling to find an answer in Task 4 . They actually said 'I cannot remember'. Sarah may have had similar problems but she did not vocalise these. She simply offered an answer, which ended up being an inappropriate one on many occasions. Given that the control group children are some 2-4 years younger than Sarah, this would suggest that Sarah's performance on the complex inferential questions, as presented in tasks 2 and 4 particularly, is developmentally problematic.

\section{DISCUSSION}

This is a small single-case study which focuses on a narrow area of a child's pragmatic functioning. It would have been useful and interesting to extend the quantity of information about the case (including data on cognitive functioning), but this was not possible. Similarly, a larger control sample would have added weight to the study. The results need to be interpreted with these limitations in mind, paying particular attention to the lack of generalisability of the observed tendencies. However, the study draws attention to a potentially interesting area of pragmatic investigation and suggests possibilities for future work.

By focusing on the nature of adult questions and the (in)appropriacy of Sarah's answers we have moved some way towards understanding why Sarah may have difficulty in conversations and in school and why she may have been considered pragmatically impaired by her speech and language therapist and her class teacher. We are also nearer to understanding why Sarah's linguistic and communication difficulties may be manifested intermittently.

This study suggests that Sarah's communication problems are not likely to stem from linguistic dysfunctioning alone but are likely to involve processing of inferential meaning. Data has been used to show a lack of a clear relationship between the grammatical form of the adult question and Sarah's answers. The one tendency involving 'Why' questions can be interpreted with the view to supporting the overall conclusions. If Sarah's problems with inferential meaning were real enough then it is not at all surprising that she would have problems with 'Why' questions, which are functionally and conceptually complex and which demand high levels of inferencing. The data further suggests why Sarah may create an initial impression of being a competent conversationalist, despite her problems with comprehension. Her problems may not be consistently manifested in spontaneous conversations, because they may not consistently require the level of inferencing which causes the problems. The situation is likely to be different in the school context where complex processing 
demands are made in the form of inferential questions and it does not therefore seem all too surprising that Sarah is failing in school.

The current study shows that Sarah performs more poorly than younger (by 2-4 years) linguistically normal control subjects on all four tasks and particularly in tasks 2 and 4 . This poorer performance is particularly marked with regard to the questions which require manipulation of inferential meaning. This lends further support to the suggestion that these types of question are problematic for Sarah. The study does not enable us to determine whether these problems stem from difficulty with inferencing per se, from difficulty with inferencing from memory or whether the problem is tied to the amount of contextually available information (for example, visual clues) or lack of world knowledge (or from combinations of these possibilities). It is known that Sarah's answers to many of the questions suggest that she had a reasonable idea of what the pictures and stories were about and therefore lack of world knowledge may not be a viable explanation. For instance, the first question in the Flood picture asked 'What has happened?' to which Sarah replied 'The water has flooded', thus suggesting that she was able to piece together sufficient information from the picture and her world knowledge to come up with an appropriate answer. The comprehension problems started to surface when she had to put visually/auditorily presented information together with hypothetical and assumed information. Some of the questions seem to require integration of visually presented information with prior knowledge while others require construction of hypothetical situations on the basis of minimal given input. This may relate to different levels, or types of, inferencing, reflecting different processing and conceptual demands. This would provide a way forward for looking at data from pragmatically impaired children.

When children become competent comprehenders of language this process can be said to involve an increasing ability to use context in interpreting meaning and to deal with indeterminacy in language. In relation to Sarah, we can say that she seems to have problems with becoming independent from the physical situational context in discerning meaning and therefore seems to have difficulty with processing of input which requires her to go beyond readily available information into high-level mental manipulation of concepts and meaning.

Given the profile of Sarah's difficulties, which have become evident in this study, we may now ask whether these difficulties could justifiably be described as reflecting pragmatic impairment. If we return to the pragmatic profiles which were performed on the data, they did not single out Sarah as being 'pragmatically impaired', which may not be surprising since the focus of these profiles is on surface behaviours and mechanics of conversation and, indeed, Sarah is relatively proficient at conversational skills.

Could problems with comprehension of inferential meaning be called 'pragmatic'? If we accept that comprehension of sentences goes beyond the construction of a propositional representation (i.e. linguistic comprehension) to integration of a propositionally presented knowledge with world knowledge (i.e. pragmatic comprehension) and that this integration (i.e. inferencing) is involved in comprehension of inferential meaning then problems with comprehension of inferential meaning can be called pragmatic comprehen- 
sion problems. Inferencing enables the listener to go beyond what has been explicitly mentioned and in this way inferencing is central to pragmatic comprehension. Sarah's comprehension difficulties could then be called pragmatic comprehension difficulties and her communication difficulties could be attributed, at least partly, to pragmatic comprehension. The term 'pragmatic impairment' would then be an appropriate description of the type of difficulty experienced by Sarah. It would also be reasonable to suggest that there are subgroups of pragmatically impaired children and that some could be said to have 'pragmatic-inferential' impairment, which would involve (primary) difficulty with the comprehension of inferential or pragmatic meaning. How this relates to cognition is, however, a further important question, as is the relationship of this to executive or frontal lobe function.

\section{REFERENCES}

Adams C, DVM Bishop (1989). Conversational characteristics of children with semantic-pragmatic disorder I: Exchange structure, turntaking, repairs and cohesion. British Journal of Disorders of Communication 24: 122-239.

Baltaxe CAM, N D'Angiola (1992). Cohesion in the discourse interaction of autistic, specifically language-impaired and normal children. Journal of Autism and Developmental Disorders 22: 1-21.

Bishop D (1982). Test for Reception of Grammar (TROG). London: Medical Research Council.

Bishop DVM (1991). The underlying nature of specific language impairment. Journal of Child Psychology and Psychiatry 35: 3-66.

Bishop DVM, Adams C (1989). Conversational characteristics of children with semantic-pragmatic disorder I: Exchange structure, turntaking, repairs and cohesion. British Journal of Disorders of Communication 24: 211-240.

Bishop DVM, Adams C (1991). What do referential communication tasks measure? A study of children with specific language impairment. Applied Psycholinguistics 12: 199-215.

Bishop DVM, Adams C (1992). Comprehension problems in children with specific language impairment: literal and inferential meaning. Jouranl of Speech and Hearing Research 35: 119-129.

Bishop DVM, Rosenbloom L (1987). Classification of childhood language disorders. In: W Yule, M Rutter (eds). Language Development and Disorders: Clinics in Developmental Medicine: Oxford: MacKeith Press.

Bishop D, Hartley J, Weir F (1994). Why and when do some language-impaired children seem talkative? A study of initiation in conversations of children with semantic-pragmatic disorder. Journal of Autism and Developmental Disorders 24: 177-197.

Craig HK, Evans JA (1993). Pragmatics and SLI: within-group variations in disourse in discourse behaviours. Journal of Speech and Hearing Research 36: 777-789.

Conti-Ramsden G, Gunn M (1986). The development of conversational disability: a case study. British Journal of Disorders of Communication 21: 339-351.

Crais ER, Chapman RS (1987). Story recall and inferencing skills in language/learning disabled and nondisabled children. Journal of Speech and Hearing Disorders 52: 50-55.

Crystal D, Fletcher P, Garman M (1976). Grammatical Disability in Children. London: Edward Arnold.

Culloden M, Hyde-Wright S, Shipman A (1986). Non-syntactic features of 'Semantic-Pragmatic' disorders. In: Advances in Working with Language Disordered Children. ICAN.

Dunn LM, Whetton C, Pinitilie O (1982). The British Picture Vocabulary Scale. Windsor: NFER-Nelson.

Fey ME, Leonard LB (1983). Pragmatic skills of children with specific language impairment. In: TM Gallagher, CA Prutting (eds). Pragmatic Assessment and Intervention Issues in Language. San Diego; College-Hill Press.

Hyde-Wright S, Cray B (1991). A teacher's and a speech therapist's approach to management. In: K Mogford-Bevan, J Sadler (eds). Child Language Disability (Vol 2: Semantic and Pragmantic Difficulties). Clevedon: Multilingual Matters.

Johnson-Laird P (1983). Mental Models. Cambridge: Cambridge University Press.

Johnston J R (1992). Cognitive abilities of language-impaired children. In: P Fletcher, D Hall (eds). Specific Speech and Language Disorders in Children. London: Whurr.

Jones S, Smedley M, Jennings M (1986). Case study: a child with high level language disorder, characterised by syntactic, semantic and pragmatic difficulties. In: Advances in Working with Language Disordered Children. ICAN. 
Kelly TP, Borrill HS, Maddell DL (1996). Development and assessment of executive function in children. Child Psychology and Psychiatry Review 1: 46-51

Leinonen E, Smith BR (1994). Appropriacy judgements and pragmatic performance. European Journal of Disorders of Communications 29: 77-84.

McTear M (1985). Children's Conversation. Oxford: Blackwell.

McTear M, Conti-Ramsden G (1992). Pragmatic Disability in Children. London: Whurr.

Milosky LM (1992). Children listening: the role of world knowledge in language comprehension. In: RS Chapman (Ed.). Processes in Language Acquisition and Disorders. St Louis: Mosby Year Books.

Oakhill J (1984). Inferential and memory skills in children's comprehension of stories. British Journal of Educational Psychology 54: 31-39.

Oakhill J, Yuill N (1986). Pronoun resolution in skilled and less-skilled comprehenders: effects of memory load and inferential complexity. Language and Speech 29: 25-37.

Oakhill J, Yuill N, Parkin A (1986). On the nature of the difference between skilled and less-skilled comprehenders. Journal of Research in Reading 9: 80-91.

Parnell MM, Amerman JD (1983). Answers to WH questions: research and application. In: TM Gallagher, CA Prutting (eds). Pragmatic Assessment and Intervention Issues in Language. San Diego: College-Hill Press.

Prutting CA, Kirchner DM (1983). Applied pragmatics. In: TM Gallagher, CA Prutting (eds). Pragmatic Assessment and Intervention Issues in Language. San Diego: College-Hill Press.

Rapin I, Allen DA (1983). Developmental language disorders: nosologic considerations. In: U Kirk (Ed.). Neuropsychology of Language, Reading and Spelling. New York: Academic Press.

Rapin I, Allen DA (1987). Developmental dysphasia and autism in preschool children: characteristics and subtypes. Proceedings of the First Symposium of Specific Speech and Language Disorders in Children (AFASIC) 20-35.

Renfrew C (1969). The Bus Story. Oxford: Renfrew.

Shields, Varley JR, Broks P, Simpson A (1996). Social cognition in developmental language disorders and high-level autism. Developmental Medicine and Child Neurology 38: 487-495.

Smith BR, Leinonen E (1992). Clinical Pragmatics. London: Chapman \& Hall.

Sperber D, Wilson D (1986). Relevance: Communication and Cognition. Oxford: Blackwell.

Stevenson RJ (1993). Language, Thought and Representation. Chichester: Wiley.

Vance M, Wells B (1994). The wrong end of the stick: language impaired children's understanding of non-literal language. Child Language Teaching and Therapy 10: 23-46.

Weismer SE (1985). Constructive comprehension abilities exhibited by language-disordered children. Journal of Speech and Hearing Research 28: 175-184.

Address correspondence to Dr Eeva Leinonen, Department of Linguistics, University of Hertfordshire, Watford Campus, Aidenham, Watford, WD2 8AT, UK.

Received March 1996; revised version accepted November 1996. 